\title{
0 Constitucionalismo entre a Fragmentação e a Privatização: Problemas Evolutivos do Direito e da Política na Era da Governança Global
}

\section{Pablo Holmes}

Instituto de Ciência Política (Ipol), da Universidade de Brasília (UnB), Brasília, DF, Brasil. E-mail: pabloholmes@unb.br

\section{INTRODUÇÃO}

ertamente não seria exagero falar em um giro cosmopolita na imaginação teórica do início do século XXI (Beck, 1999:319). De fato, mesmo aqueles que resistem em aceitar a afirmação de Niklas Luhmann, segundo a qual há apenas uma sociedade mundial sobre o globo (1997a:67ss), são obrigados cada vez mais a lidar com um vocabulário "transnacional", "pós-nacional", "globalizado" e "cosmopolita", que parece gradualmente prevalecer nos mais diferentes campos teóricos e empíricos das Ciências Sociais.

No interior do pensamento jurídico e político há um giro similar. A discussão entre teóricos da política e do direito está, hoje, intimamente relacionada à emergência de uma ou diversas novas ordens jurídicas e políticas para além do Estado nacional (Brunkhorst, 2007:63-109) e às implicações destas tendências para novas formas de lidar com os paradoxos da decisão jurídica e política (Koskenniemi, 2008:65-89; Fischer-Lescano e Teubner, 2006:10-33). Se observarmos as revistas do sistema científico global, é fácil perceber que cada vez mais surgem questões que dizem respeito a uma tecnificação da semântica jurídica (ver, por exemplo, Howse, 2002:94-117; Kennedy, 2005:5-28), uma fragmentação crescente do direito internacional (Koskenniemi, 2009:795-798) e uma transformação das formas de governança (Djelic e

DADOS - Revista de Ciências Sociais, Rio de Janeiro, vol. 57, n-4, 2014, pp. 1137 a 1168. 
Sahlin-Andersson, 2006:1-30). E esses temas se tornam centrais não apenas na reflexão teórica, como também nas pesquisas empíricas sobre os sistemas político e jurídico. Paralelamente a isso, emergiu, nos últimos anos, um discurso acerca do que poderiam ser momentos constitucionais de regimes jurídicos globais: uma tentativa de dar conta de transformações na própria reflexividade de regimes de governança supranacionais e transnacionais, de acordo com a qual a reflexividade desses regimes não mais corresponderia às estruturas da constitucionalização política centrada no Estado nacional (Walker, 2002:317-340; Teubner, 2004:3-29).

O objeto do presente artigo é, assim, a emergência desses novos fenômenos no nível que se convenciona chamar de governança global. A partir de uma leitura da teoria social dos sistemas, serão observados os processos de transformação do direito e da política graças à crescente integração transnacional da sociedade mundial. Assim, o processo de fragmentação dos regimes globais de governança é associado a uma radicalização do processo de diferenciação funcional da sociedade mundial, que exigiria a relativização de algumas premissas típicas do pensamento jurídico-político que emergiu do processo nacional de constitucionalização. Nesses termos, a expansão de formas descentralizadas e heterárquicas de comunicação funcionalmente diferenciada limitaria as pretensões do sistema político de funcionar como centro da sociedade, submetendo todas as dinâmicas sociais aos desígnios da forma constitucional democrática centrada no Estado. À fragmentação dos regimes de governança globais corresponderia, enfim, um processo de transformação da forma constitucional moderna, com diversas consequências para o funcionamento dos mecanismos de regulação social.

O artigo se dedica a esclarecer, portanto, quais são essas mudanças estruturais e semânticas do direito e da política nos planos transnacional e supranacional ${ }^{1}$ e as suas consequências para o discurso reflexivo no interior desses sistemas: ou seja, para seu "constitucionalismo". Longe de defender uma perspectiva normativa, que insista nas virtudes da teoria democrática ou postule alternativas, por meio do constitucionalismo, para uma suposta "crise da democracia", trata-se aqui de observar sociologicamente as transformações estruturais e semânticas do poder e do direito na sociedade mundial transnacionalizada atual, especulando acerca de possíveis consequências dessas transformações do constitucionalismo. 
A seguir, conceituarei e contextualizarei sociologicamente a semântica da chamada fragmentação do direito mundial e a incipiente deterioração da semântica do constitucionalismo democrático no sistema político da sociedade mundial graças à sua crescente fragmentação. Depois, observarei o que parecem ser tendências de transformação das estruturas jurídicas e políticas no plano transnacional e supranacional, com a consequente mudança do balanço entre poder público e privado. Tal diagnóstico exigiria uma concepção de exercício do poder que não mais se limite às estruturas constitucionais do Estado democrático, articulada na noção de exclusividade da autoridade pública como autoridade legítima, típicas de teorias políticas liberais. Precisaríamos, em lugar disso, levar a sério a emergência de novas formas de poder privado, o que acarretaria uma verdadeira transformação da "forma constitucional" do direito na sociedade mundial. A partir disso, reconstruirei algumas consequências dessa "transformação constitucional" para o funcionamento dos mecanismos regulatórios do direito, no que se convenciona chamar "governança global". Por fim, lançarei uma reflexão acerca das possíveis consequências societais dessas transformações no sistema político e jurídico.

Se regimes transnacionais e supranacionais de governança parecem incorporar cada vez mais tarefas regulatórias, em grande medida constrangendo as possibilidades de ação estatal orientadas politicamente, ao mesmo tempo em que eles parecem funcionar mediante uma forma distinta de relação entre direito e política, regulação e poder, será que elas podem desempenhar as mesmas funções que os procedimentos juridicamente regulados do sistema político cujo centro era o Estado nacional? Quais as consequências dessas mudanças para os imperativos políticos de inclusão social e igualdade de direitos formais e materiais típicos do constitucionalismo democrático moderno?

\section{TRANSFORMAÇÕES ESTRUTURAIS DO DIREITO NA SOCIEDADE MUNDIAL: A EMERGÊNCIA DE ORDENS PLURAIS PARA ALÉM DO ESTADO NACIONAL}

Ao se observarem as tentativas de descrição da ordem político-jurídica global nos nossos dias, percebe-se facilmente uma inflação teórica de termos como "pluralismo jurídico" (Teubner, 1996:199-220; Krisch, 2006:247-278), "pluralismo societal" (Willke, 2003:10-26), "pluralismo constitucional" (Walker, 2002:317-383) etc. Segundo entendo, esse é o sintoma natural do fato de que não existe uma organização global ca- 
paz de funcionar como centro do sistema político global. Em outras palavras, a ausência de um Estado mundial corresponde à emergência de uma multiplicidade de autodescrições tanto do sistema político quanto do sistema jurídico da sociedade mundial em seus diversos níveis, sobretudo no transnacional e no supranacional.

A ideia de um direito mundial fragmentado ou plural não permite uma definição apressada baseada em perspectivas teóricas do passado. Longe de ser um problema meramente semântico, referido a uma descrição adequada de fenômenos sociais, a noção de que há uma "fragmentação do direito internacional" encontra apoio em mudanças estruturais do direito e da política (Amstutz e Karavas, 2009:645-650) que podem ser inclusive estudadas empiricamente. Em linguagem de teoria dos sistemas, essas transformações se deixam atribuir à diferenciação funcional e à sua dinâmica de globalização, que sobrecarregam o constitucionalismo democrático nacional. Se a ordem democrática nacional nunca houvera sido completamente autônoma, agora ela tem que abrir mão de qualquer pretensão forte de autonomia (cf. Koskenniemi, 2008:72-74).

Por um lado, a ordem jurídica internacional, baseada em tratados e acordos vinculados à autonomia soberana dos Estados para aderir, ou não, à regulação internacional parece ser objeto de uma profunda transformação em razão de sua crescente fragmentação e tecnificação. A multiplicidade de obrigações a que um Estado dá seu consentimento é tanta, que se tornou comum a colisão entre regimes diversos, sem que fique claro qual ordem deve prevalecer em cada caso. De fato, cada vez menos autores ainda falam em uma ordem jurídica internacional consistente e unitária. E como consequência direta da fragmentação identifica-se um grau crescente de especialização técnica na operação do direito internacional (Koskenniemi, 2007:9-14). Por outro lado, tratados internacionais estabelecendo novos regimes jurídicos parecem criar obrigações para os Estados nacionais muitas vezes "sem ou mesmo contra" a sua vontade (Tomuschat, 1993:195-237), uma consequência do fato de que a crescente complexidade de dinâmicas sociais produz esferas de regulação que os Estados não são mais capazes de regular e que, ainda assim, produzem efeitos dentro do seu território ou na forma de pressões externas políticas e econômicas.

Com efeito, a ausência de autoridades soberanas com poder suficiente para produzir normas vinculantes em âmbito global corresponde pa- 
radoxalmente a uma crescente densificação de interações e mecanismos de regulação supranacionais e transnacionais (Holmes, 2013:172-184). Não é difícil de observar uma extensa proliferação de domínios epistêmicos funcionais diferenciados no interior do direito internacional, construídos na maioria das vezes de forma ad hoc, com a participação não apenas de Estados, mas de uma pluralidade de atores, inclusive muitos deles privados ou semiprivados (FischerLescano e Teubner, 2007:26).

Nesse contexto de transformação do papel do Estado, fala-se cada vez mais em governança em lugar de governo, definindo-se "governança global" como "a soma de muitos mecanismos por meio dos quais indivíduos e instituições, públicas e privadas, administram seus assuntos comuns" ${ }^{\prime 2}$. A governança global envolveria, assim, além de Estados, organizações não governamentais, movimentos sociais, corporações transnacionais e outros atores dos mercados, interagindo em uma esfera cada vez mais permeada por meios de comunicação de massa mundiais, na tarefa de criar regulações e coordenar as ações desses atores no nível global (o que, ao menos indiretamente, também vincula as interações que se dão no interior dos Estados nacionais). O velho debate sobre jus cogens no direito internacional parece ser, em grande medida - embora não completamente-, dissolvido sob a pressão - não necessariamente coativa - de imperativos funcionais de diferentes sistemas como o mercado financeiro, a comunicação de massa, os esportes, a ciência, a saúde etc. (Willke, 2003:129-142). E também regimes jurídicos transnacionais, sobretudo na esfera da regulação econômica, parecem desenvolver formas extremamente efetivas de cogência normativa (Renner, 2011:73-87). Casos como os das cortes de arbitragem de investimentos, vinculadas à Convenção para a Resolução de Conflitos Relativos a Investimentos entre Estados e Nacionais de Outros Estados, de 1965, chamam a atenção, pelo fato das decisões do Centro Internacional para a Resolução de Conflitos Relativos a Investimentos (ICSID, na sigla em inglês) poderem limitar não só a ação política de Estados nacionais (do Poder Executivo) no campo da política econômica, o que envolve muitas vezes um cálculo político de oportunidade, mas por também poderem limitar a efetividade de decisões judiciais de cortes nacionais, inclusive cortes constitucionais (Renner, 2011:127-168) ${ }^{3}$. Uma dinâmica que claramente limita de modo assimétrico Estados centrais e periféricos - submetendo mais os últimos do que os primeiros -, mas que, ao mesmo tempo, coloca em xeque o para- 
digma jurídico-constitucional da supremacia das constituições nacionais.

Se a teoria original dos regimes internacionais - formulada pela teoria das relações internacionais, no campo das Ciências Políticas - entendia que regimes "não deveriam ser interpretados como elementos de uma nova ordem internacional além do Estado-nação" (Keohane, 1984:63), parece que a política mundial entre Estados é gradativamente substituída por um tipo de barganha cooperativa baseada na acomodação interativa de interesses e mecanismos funcionais específicos de cada área de regulação, no interior da qual os Estados são apenas atores entre outros (Fischer-Lescano e Teubner, 2006:17-19; Cassese, 2005a:973-993). Nessa dinâmica, entram em ação não apenas os Executivos nacionais, que sempre tiveram que lidar com questões de "relações internacionais", mas também o Judiciário e o Legislativo, o que coloca em xeque a pretensão normativa de autonomia constitucional dos Estados. Além disso, regimes globais passaram a ser definidos não só a partir da observação empírica de um conjunto de "princípios, valores e regras" faticamente vigentes em um determinado setor de regulação (Krasner, 1982:185-187; Keohane, 1984:57), para ganhar status de verdadeiras ordens jurídicas (Abbot et al., 2000), com poder adjucatório e graus importantes de juridificação e cogência (Fischer-Lescano e Teubner, 2006:19-21) ${ }^{4}$. Vários exemplos de regimes jurídicos transnacionais e supranacionais poderiam ser citados em que os Estados funcionam como stakeholders mais ou menos importantes, a depender do caso.

Regimes jurídicos transnacionais, por exemplo, constituem-se frequentemente ao redor de organizações privadas ou de jurisdições privadas, desenvolvendo a pretensão de regular, em nível global, um setor específico de processos sociais, sem ser limitados pelas fronteiras territoriais nacionais. Esse seria o caso do regime de governança da internet, a cargo da atuação do ICANN (Internet Corporation of Assigned Names and Numbers), uma instituição privada - embora originada por iniciativa do poder público dos Estados Unidos da América - que opera sem qualquer fundamento em um tratado internacional (Von Bernstorff, 2004:259). Seria ainda o caso da lex mercatoria, uma ordem na qual as obrigações assumidas por atores privados por meio de mecanismos contratuais estabelecem as próprias redes de adjudicação responsáveis pela administração judicial de possíveis controvérsias (Hatzimihail, 2008:170-172). 
Já regimes jurídicos supranacionais, embora normalmente se originem de um tratado internacional, podem também constituir ordens jurídicas com a pretensão de submeter Estados nacionais à sua soberania, $\mathrm{o}$ que, mesmo sem precisar verificar completamente, gera constrangimentos e irritações no nível nacional que muitas vezes condicionam os processos políticos dos diversos poderes internos. O melhor exemplo, nesse caso, é sem dúvida a União Europeia, cujo ordenamento jurídico funciona sob o princípio da supremacia do direito comunitário (cf. Bohman, 2004:318-325), mas exemplos de constrangimentos a políticas públicas, a processos legislativos ou mesmo a decisões judiciais, em diversos níveis, por decisões de organizações supranacionais como a OEA, ONU ou Mercosul, poderiam ser facilmente lembrados.

A desnacionalização do discurso jurídico e político, no nível semântico, só pode ser vista, assim, como uma reação a alterações do direito e da política no nível estrutural da sociedade mundial, que parecem comprometer a capacidade do constitucionalismo nacional de definir os limites das operações jurídicas no direito mundial (Stolleis, 2004:19-23; Walker, 2002:319-332). Mesmo que ordenamentos jurídicos nacionais ainda representem importantes subsistemas funcionando como um entorno cooperativo - ou hostil - ao direito supranacional e transnacional (Amstutz e Karavas, 2009:650-654), é difícil pensar que, no contexto de uma sociedade mundial altamente dinâmica e transnacionalizada, o direito nacional ainda possa ser considerado um regime jurídico infenso aos influxos comunicativos desses regimes globais (Teubner, 1997:8-11). E até mesmo os que preferem uma posição mais restritiva em relação aos diagnósticos mais radicais acerca da globalização política e jurídica parecem admitir que diálogos, influências e pontes de transição parecem ser inevitáveis para que os sistemas constitucionais estatais continuem a desempenhar suas operações de modo minimamente adaptado a seu entorno social (Neves, 2009:115-132).

O desenvolvimento do direito mundial no curso do processo de globalização, sobretudo graças à dinâmica de transnacionalização da sociedade mundial, tende, portanto, a se caracterizar pelo fato de que regimes globais emergentes se vinculam cada vez mais à racionalidade de seu próprio campo de regulação (Koskenniemi, 2007:4-9). Uma Babel global de vocabulários técnicos, na qual não há linguagem comum a funcionar como uma comunicação geral (Fischer-Lescano e Teubner, 2006:10-25; Teubner, 1996:200-220), põe assim em risco, ou ao menos 
relativizam a centralidade das velhas formas estáveis de acoplamento estrutural do sistema jurídico com os sistemas políticos.

E na maioria das vezes regimes não estatais não dispõem de nenhum mecanismo semelhante a uma constituição política ${ }^{5}$, embora possam colidir com ordens político-constitucionais nacionais (Vesting, 2009:620-626). Essas colisões entre os diferentes ordenamentos jurídicos, por outro lado, não podem mais contar exclusivamente com soluções jurídicas baseadas nas técnicas amplamente difundidas do direito público e da jurisdição constitucional nacional ${ }^{6}$.

\section{CONSTITUCIONALIZAÇÃO FUNCIONAL? A TRANSNACIONALIZAÇÃO DA GOVERNANÇA E A EMERGÊNCIA DO PODER REGULATÓRIO PRIVADO}

Uma sociedade mundial cujas organizações e sistemas funcionais se transnacionalizam de modo consistente e acelerado certamente continua exigindo, para a reprodução de sua própria diferenciação, mecanismos capazes de estabilizar e tornar minimamente congruentes as expectativas normativas para a operação de seus processos sociais de comunicação (Fischer-Lescano, 2005:62-66). Essa é uma exigência do próprio fenômeno de globalização funcional, já que só assim a sociedade mundial pode manter a comunicação transnacional operativa.

Os regimes de governança supranacionais e transnacionais emergentes, por sua vez, também necessitam de regras de segunda ordem, capazes de estruturar a sua reflexividade e, portanto, estruturar seus processos de modo - relativamente - independentes das ordens estatais, possibilitando sua reprodução como verdadeiros "regimes jurídi$\cos ^{\prime \prime}$. Nesse ponto, Teubner reivindica, acompanhando formulação de Niklas Luhmann (1990:184-193), que "todo processo de juridificação simultaneamente contém normas constitucionais latentes" (Teubner, 2004:15) ${ }^{7}$. Não mais sendo capazes de contar com o efeito unificador assegurado por uma ordem constitucional política (Grimm, 2001:489-506), regimes jurídicos fragmentados, transnacionais e supranacionais podem estabelecer suas próprias instituições e mecanismos para a gestão da contingência interna do código jurídico e ganhar uma dimensão autorregulatória que, embora não corresponda à forma político-jurídica do Estado nacional, tem pretensão de autonomia frente aos Estados nacionais e à ordem internacional dos tratados.

Em outras palavras, regimes globais podem desenvolver, nos níveis de reprodução transnacionais e supranacionais, um discurso interno so- 
bre a validade de suas normas jurídicas e decisões sem qualquer referência direta a uma ordem política. Poder-se-ia notar a emergência de normas de segunda ordem capazes de administrar o problema da validade jurídica, o que leva alguns autores a reivindicar a existência de "constituições civis" (Teubner, 2012:120-139).

Uma observação empírica da emergência de ordens transnacionais e supranacionais nos faz sensíveis ao caráter extremamente fragmentado e heterogêneo dos seus respectivos regimes regulatórios (Cutler, 2004:28), o que em parte relativiza o diagnóstico um tanto homogêneo de uma constitucionalização civil, tal qual proposta por Teubner. Por um lado, há graus bastante distintos de juridificação, a depender do setor social regulado (Abbot et al., 2000:404-408). Enquanto regimes jurídicos, como por exemplo a lex mercatoria, incorporam, em larga medida, mecanismos jurídicos de reprodução regulatória; outros regimes, como por exemplo a governança do sistema financeiro (que também é bastante fragmentado internamente), ganham formas menos jurídicas de regulação e muito mais baseadas em redes informais de comunicação. Por outro lado, os regimes podem ter a presença maior ou menor de atores estatais. Enquanto o regime de governança supranacional da segurança, cujo centro é o Conselho de Segurança da ONU, parece se apoiar em grande medida na força militar e política - assimétrica - dos Estados nacionais, regimes jurídicos transnacionais como a governança da internet ou dos esportes parecem exibir um peso maior de instituições e organizações privadas.

De todo modo, uma descrição teórica da nova constelação de mecanismos de governança global teria, fatalmente, que levar em conta um desafio estrutural à forma constitucional tal qual ela é descrita no modelo de acoplamento entre direito e política do constitucionalismo democrático estatal. Nesse sentido, é inegável a constatação de que há um aumento de importância de atores privados no exercício de autoridade, regulação e poder. Isso seria acompanhado por uma gradual transformação da semântica jurídica e política nos termos de um aumento da importância do poder não estatal (privado) nas formas de regulação (Hall e Biersteker, 2006:3-9). Tal constatação não depende de uma referência à formulação abstrata de teóricos sistêmicos, como por exemplo Gunther Teubner (2004:12-15), acerca de um pluralismo transnacional de constituições civis (Fischer-Lescano e Teubner, 2006:57-65). Basta, em lugar disso, uma referência à tendência cada vez mais conhecida de evolução das formas de regulação transnacional, e mesmo nacional, de 
uma adaptação aos modelos da chamada governança corporativa (Picciotto, 2011:9-15, 108-121), para nos tornarmos sensíveis ao fato de que há uma relativa "privatização" da linguagem regulatória em nível global.

Diversos autores têm chamado a atenção para o fato de que a semântica da governança corporativa domina não apenas organizações transnacionais desvinculadas de mecanismos políticos de constitucionalização, como também organizações internacionais e supranacionais e mesmo as formas contemporâneas de administração no interior do Estado nacional (Crouch, 2009:879-895; Vasilache, 2009). Operações militares e humanitárias, políticas de desenvolvimento (Santos, 2006:282-286) e mesmo o uso de forças internas de segurança parecem ser submetidas a regimes em que os mecanismos de controle e decisão se assemelham às estruturas de governança privada. Mesmo no caso de organizações como a Organização Mundial do Comércio (OMC) e seu sistema de controvérsias, teoricamente resultante de tratados internacionais, a operação do regime é centrada cada vez mais ao redor de escritórios de advocacia multinacionais, "verdadeiros mercantes de normas (merchants of norms), exercendo clara autoridade moral, em adição à sua autoridade de mercado, por meio de um monopólio privado na administração dos processos decisórios" (Cutler, 2004:31).

Outros autores falam em uma transformação semântica e uma mudança na mentalidade jurídica em relação a vários aspectos das atividades regulatórias nos planos transnacionais e supranacionais (Caruso, 2007:1-74), algo que corresponderia, em parte, à tendência, no plano nacional, a uma "marketização" do setor público, que incorporaria na prática interna da administração dos Estados nacionais a lógica de funcionamento do mercado (Crouch, 2009:879-885). Essa transformação vem associada a um esvaziamento das instâncias políticas baseadas em processos democráticos e, do ponto de vista do direito, faz com que setores regulatórios globais (transnacionais e supranacionais), antes vistos como legítimos apenas por estarem acoplados às práticas, vocabulários e organizações do sistema político, passem também a ser descritos por meio da linguagem do direito privado (Caruso, 2007:33-42). Mesmo em realidades constitucionais em que se viu uma constitucionalização mais recente, como a latino-americana, imperativos para a incorporação de dinâmicas típicas do mercado e do setor privado no interior do direito administrativo se tornaram uma constante a partir da década de 1990 (Castro, 2014:35-36). 
A emergência do poder regulatório privado não parece se limitar, contudo, às estruturas formalizadas de regimes organizados juridicamente. Paralelamente às ordens com maior nível de institucionalização e juridificação surge uma série de novos mecanismos indiretos de regulação, capazes de exercer autoridade de modo legítimo e vinculante, sem se apoiar nas estruturas de soberania do direito público constitucional (Cutler, 2004:28). Além da possibilidade de aproveitar sua alta mobilidade e as facilidades crescentes para a criação de holdings, cartéis e redes transnacionais de executivos (Carroll e Fenema, 2002:393-400), organizações privadas de vários tipos (não apenas empresas) podem se apoiar, por exemplo, na ciência para legitimar decisões regulatórias capazes de coordenar as ações de diversos atores (inclusive os Estados) em um determinado setor de governança. Empresas de consultoria e de auditoria, centros de pesquisa, instituições de treinamento e desenvolvimento, assim como comunidades de experts, são capazes de produzir tecnologias de controle social com efetiva capacidade de exercer poder regulatório, sem precisar necessariamente recorrer à força dos Estados, ou mesmo contra as pretensões regulatórias destes (Drori e Meyer, 2006:49-51).

O poder regulatório privado pode fazer uso, por exemplo, de indicadores, tanto para influenciar as decisões políticas e administrativas de estados e municipalidades, como para introduzir mecanismos de autocontrole por agentes privados econômicos e não econômicos. A explosão no número e tipos de indicadores, nos mais diversos campos (educacional, direitos humanos, ambiental, desenvolvimento), parece apontar para a multiplicação de novas formas de governança que não necessariamente exigem poder de polícia por parte de órgãos administrativos de caráter público (Rosga e Satterthwaite, 2009:279-285). Também o poder regulatório de standards e rankings parece ter crescido de modo significativo; e não só na economia (agricultura, indústria e serviços), como também em outros setores da sociedade mundial (Higgins e Hallström, 2007:696-700). Um exemplo interessante poderia ser visto na forma como políticas econômicas nacionais se orientam por indicadores e standards oferecidos por agências de rating privadas transnacionais.

Governos nacionais e órgãos supranacionais parecem cada vez mais se apoiar na produção transnacional de saber regulatório privado, o que lhes possibilita diminuir suas tarefas de regulação direta soberana. Para isso, eles atribuem autoridade a mecanismos de regulação indire- 
ta, baseados em relatórios, auditorias e mecanismos de autorregulação, que são o resultado de formas de produção de saber não necessariamente orientadas por mecanismos político-constitucionais.

Nesse sentido, não caberia comparar a emergência dessas novas tecnologias e formas de regulação com a existência de agências técnicas nacionais, visto que essas, inclusive juridicamente, permanecem submetidas aos controles jurídico-constitucionais do Estado de Direito. O que estaríamos a observar seria uma nova forma de acoplamento entre poder e direito, que não mais se dá em termos político-constitucionais fundados em ordens democráticas e procedimentos políticos inclusivos. Em lugar disso, ganha importância a emergência de ordens privadas e arranjos autorregulatórios baseados no surgimento de mecanismos alternativos de resolução de conflitos tais quais a arbitragem (Willke, 2003:82-83). Tudo isso parece reconfigurar as relações constitucionais entre o público e o privado. Como observa Cutler:

A atribuição de funções públicas a atores privados desafia de modo direto as teorias liberais e democráticas do direito e da governança. De fato, imputar autoridade política e de controle à ação de atores privados "viraria ao avesso a ideia de democracia representativa". Isso ameaçaria "a arte liberal da separação" que serve de suporte para a separação entre Estado e sociedade; público e privado; governo e mercado; política e economia (2004:33).

\section{GOVERNANÇA GLOBAL E NOVAS ESTRUTURAS JURÍDICO-POLÍTICAS: UMA ORDEM POLÍTICO-JURÍDICA PÓS-ESTATAL?}

A emergente semântica regulatória global parece dar rédeas ainda mais livres à fragmentação radical das racionalidades funcionais, num efeito de retroalimentação. Ao dispensar, em grande medida, formas políticas de constitucionalização da sua produção regulatória, o direito transnacional e supranacional permite uma proliferação ainda mais abrangente de regimes regulatórios funcionalmente diferenciados e uma consequente fragmentação das racionalidades funcionais, as quais são o motor do processo de transnacionalização. Diferentes formas de racionalidade podem então usar as vantagens oferecidas pelas novas formas de regulação, o que funciona como um feedback que realimenta a fragmentação estrutural do direito global e seu desacoplamento da política nacional. 
Essa transformação estrutural dos acoplamentos do direito com os setores regulados não significa, necessariamente, um refluxo dos Estados nacionais como organizações importantes do sistema político. Em realidade, nunca houve tantos Estados organizados no globo terrestre como é possível verificar em nossos dias. E, de fato, como apontava Luhmann, a sociedade mundial não pode se dar ao luxo de prescindir de Estados, organizações essenciais às estruturas de diferenciação funcional da ciência, educação, saúde, economia etc., em vastas faixas territoriais (2000:93). Um olhar atento sobre os acontecimentos posteriores à crise financeira global de 2008 fatalmente nos alertaria para o papel central que os Estados ainda desempenham, inclusive na governança da economia global. Nesse sentido, a emergência de novas formas de regulação parece provocar muito mais uma reprogramação do poder e do direito em níveis globais, o que constrange e influencia as dinâmicas político-jurídicas nacionais, do que uma despedida do Estado nacional. A rigor, "globalização e Estados nacionais não se opõem, pois os Estados nacionais também foram em grande medida globalizados" (Mann, 2010:21).

Por outro lado, seria também um erro insistir que viveríamos uma época de "desregulação". Em lugar disso, faz sentido postular a existência de uma crescente inflação regulatória como consequência da multiplicação de ordens normativas e regimes de governança transnacional e supranacional. Se observarmos, além disso, que a regulação social cada vez menos se limita às estruturas condicionais do direito e aos mecanismos coercivos do Estado, ampliando-se para uma série de novos mecanismos regulatórios mais flexíveis e informais, resta claro que, mesmo a assim chamada ordem neoliberal, produz muito mais uma proliferação regulatória que uma "desregulação" social. A pergunta mais importante deve ser, porém, sob que regime constitucional a regulação emergente é produzida.

Com efeito, o incremento do poder privado exige, a rigor, mais regulação. Algo que a lógica sociológica pode certamente ajudar a explicar, pois o aumento de complexidade derivada da dupla contingência multiplicada pela quantidade de atores que necessitam coordenar suas ações sem poder contar com o poder estatal como única fonte de decisões com impacto coletivo exige a multiplicação de regimes regulatórios e regulação (Braithwaite, 2005:33-35). Essa regulação parece, porém, ser produzida e administrada de forma distinta daquela típica das estruturas constitucionais da política democrática. A seguir, gosta- 
ria de apontar três fenômenos que são cada vez mais frequentemente observados nas estruturas de governança global e parecem fragilizar a lógica tradicional de funcionamento do direito e de exercício do poder regulatório, baseado no direito público dos ordenamentos constitucionais democráticos. Vou me referir a (a) uma desformalização do código jurídico, que altera o modo com que o direito é programado; (b) uma mentalidade gerencialista na reprodução do direito, que altera o tipo de processo decisório baseado na observação da contingência interna típica da dogmática moderna, e (c) um processo de formação de redes, que induz a produção de uma elite transnacional de especialistas em posição de ignorar processos políticos tanto nacionais como transnacionais.

(a) Nos últimos anos, especialmente os internacionalistas têm chamado atenção para o fato de que os regimes jurídicos especializados de direito global não operam de acordo com a forma clássica de programação condicional que costumava ser central para o sistema jurídico nos quadros tradicionais do positivismo. Para eles, o direito transnacional parece prescindir cada vez mais do tipo de programa baseado em sentenças condicionais do tipo "se..., então..." (Luhmann, 1993:195-198). Alguns juristas usam, então, a palavra "desformalização" para apontar novas formas de produção de normas e de interpretação de acordo com as quais um amplo espectro de opções de sentido é deixado livre para a escolha dos intérpretes, que devem, então, preencher essas cláusulas em branco levando em consideração demandas técnicas de racionalidades funcionais específicas (Koskenniemi, 2007:9).

Mesmo os tratados internacionais mais antigos, como a Convenção das Nações Unidas para o Direito Marítimo, de 1982, são interpretados de modo a garantir um espaço de operação cada vez maior a experts e tecnocratas, fazendo-os flexíveis e adaptáveis a imperativos funcionais, e diversos novos tratados são formulados de modo a não conter verdadeiras regras, mas apenas regulações generalizadas que deixam toda decisão substancial para especialistas (Koskenniemi, 1990:28). Além disso, regimes jurídicos transnacionais necessitam em muito menor medida dos mecanismos coercitivos próprios ao direito estatal nacional para impor suas decisões (Heyvaert, 2009). Normas e decisões neste nível podem cada vez mais ser impostas contando apenas com mecanismos de soft law, meios indiretos de influência e verificação do adimplemento dos destinatários. No caso de regimes jurídicos vinculados ao sistema econômico, as partes concernidas tenderiam, por exemplo, 
a cooperar com base em cálculos de custos que levem ao cumprimento de acordos e normas por meio de uma decisão conjunta tecnicamente justificada (Cassese, 2005b:680-684).

(b) Durante a última década, tem se tornado bastante difundida a noção de que o direito pós-regulatório se organiza ao redor de uma mentalidade gerencialista (cf. Brunkhorst, 2014) que substitui em grande medida a linguagem da política democrática baseada numa mentalidade de conflitos de interesse. A mentalidade gerencialista se expressa geralmente na linguagem da "governança", que enclausura a semântica administrativa e jurídica na linguagem regulatória tecnocrática de subsistemas funcionais especializados (Kennedy, 2009:37-67; Lang e Scott, 2009:610-614). Em lugar de mecanismos públicos de controle, fala-se em accountability; e em lugar de uma negociação política de interesses, fala-se joint decision making (Keohane, 2002:245-271). As cláusulas jurídicas brancas, retiradas expressamente da linguagem da administração empresarial e da teoria econômica neoclássica, permitem que novas formas de tomada decisão substituam os tradicionais modelos de ponderação de princípios e interpretação do cânone metodológico do direito. Para os críticos, não se trata aqui de uma mera alteração semântica, senão de um abandono da forma político-constitucional na direção de formas apolíticas de acoplamento estrutural entre o direito e outros sistemas funcionais.

O direito pós-regulatório mundial parece se basear, assim, em mecanismos de adaptação e aprendizagem cognitiva entre setores sociais especializados ou organizações transnacionais e um sistema jurídico incapaz de se impor verticalmente (Amstutz e Karavas, 2009:653-657). Assim, os especialistas dos respectivos "domínios funcionais" se tornam gradualmente os responsáveis tanto pela elaboração de normas como pelos processos decisórios mais relevantes (com base nas normas que eles mesmos elaboram), o que explicitamente rompe com a ideia tradicional de uma separação democrática de poderes. Por outro lado, a legitimidade das decisões parece então advir exclusivamente da sua pertinência funcional, numa transformação da legitimidade da regulação social como esta era entendida nos quadros do constitucionalismo democrático (Baecker, 2009:673-686; Koskenniemi, 2008:76-77).

(c) Uma vez que se tornou claro, ao longo da década de 1980, que a estrutura de organizações internacionais do pós-guerra - baseada na lógica estatal da hegemonia norte-americana sustentada pelo sistema de 
Bretton Woods - não era mais capaz de engendrar uma cooperação forçada no campo da regulação econômica mundial (Keohane, 1984:49; Willke, 2003:132), juristas e cientistas políticos tentaram entender o funcionamento dos mecanismos de governança global e de seus processos de decisão buscando observar fenômenos que vinham ganhando espaço não na superfície da política mundial organizada, mas no subsolo de uma emergente sociedade transnacional de indivíduos e atores organizacionais privados (cf. Slaughter, 2010:4-9). Nessa busca por alternativas teóricas que fossem mais aptas à observação da crescente fragmentação regulatória, sobretudo os cientistas políticos se entusiasmaram com a descrição de regimes regulatórios nos quais a cooperação entre atores internacionais e transnacionais seria baseada na convergência de interesses e visões de mundo - uma certa convergência cognitiva e epistemológica de comunidades epistêmicas (Haas, 1992:1-35) - em cada área específica de regulação (Krasner, 1982:185-202). Desde então, uma série de observações chamaram a atenção da teoria política e das relações internacionais para a existência de redes transgovernamentais, tanto entre os agentes administrativos ligados às burocracias de Estados nacionais, como entre os experts vinculados a organizações internacionais e transnacionais. AnneMarie Slaughter, entre outros autores, passou a chamar a atenção para o fato de que o Estado não estaria desaparecendo ou perdendo seu papel em função dos processos de transnacionalização, "mas desagregando-se nas instituições e organizações que o compõem" e interagindo cada vez mais "com seus homólogos estrangeiros para além de suas fronteiras" (Slaughter, 1997:18).

Redes de atores nacionais e internacionais se transnacionalizavam em verdadeiras comunidades fragmentárias formadas por tecnocratas, diplomatas, juízes e advogados responsáveis por produzir e trocar informação regulatória ao redor do globo. Para Slaughter, ao contrário de esse fenômeno significar um bloqueio às formas de reprodução comunicativa do sistema político nacional, ele poderia constituir um equivalente funcional transnacional dos mecanismos de accountability da democracia nacional por meio do fortalecimento da troca de informações e do favorecimento da cooperação inter-regimes (Slaughter, 2010:29-38). Em lugar de uma democracia fundada no Estado, poderíamos estar observando o surgimento de uma democracia desagregada, em que uma série de stakeholders controlam reciprocamente o seu poder regulatório, sem a existência de um centro último capaz de funcionar como órgão decisório de última instância. 
Os críticos dessa abordagem apontam, porém, que tais redes transnacionais têm um caráter bem distinto daquele atribuído por Slaughter. Tais redes poderiam operar muito mais como uma forma de contornar e ignorar os processos decisórios dos Estados nacionais e os procedimentos políticos de delegação de poder no direito internacional público (Zaring, 2004:547ss; Weiler, 2001:191-207). Ao invés de tornar as decisões mais informadas e mais sujeitas ao escrutínio de uma esfera pública nacional e internacional, a densificação de redes transnacionais de contatos entre agentes públicos parece tornar ainda mais invisível e informal o saber regulatório global. As redes fortaleceriam, assim, o caráter tecnocrático e apolítico da governança global, reduzindo ainda mais as decisões a problemas gerenciais, cuja resolução é reservada a profissionais especializados (Picciotto, 1997:1014-1056).

\section{CONSTITUCIONALISMO GLOBAL E INCLUSÃO/EXCLUSÃO: DESAFIOS ESTRUTURAIS PARA A EVOLUÇÃO DO DIREITO E DA POLÍTICA NA SOCIEDADE MUNDIAL}

Se partirmos de uma descrição do complexo jurídico-político moderno desde a perspectiva de uma teoria dos sistemas, é possível encontrar no interior do Estado de Direito Constitucional autodescrições que facilitam a irritação recíproca de direito e política, embora esses sistemas permaneçam diferenciados e delimitados entre $\mathrm{si}^{8}$. Ambos os sistemas projetam suas respectivas unidades em uma constituição que é ao mesmo tempo política e jurídica (Luhmann, 1990:176-183; Brunkhorst, 2009:447-464) e que serve de ponto de observação para o assim chamado constitucionalismo, uma semântica em grande medida comum a ambos os sistemas.

O sistema político e o sistema jurídico constroem por meio do direito constitucional um acoplamento estrutural que proporciona um alto nível de irritabilidade recíproca (Luhmann, 1993:422; Neves, 2008a:477-509). O direito se aproveita das prestações da política democrática para neutralizar, em alguma medida, usos seletivos do seu código, fazendo com que as regulações eleitorais e legislativas imunizem, ao menos normativamente, os usos instrumentais do direito por minorias, já que a igualdade política veda a institucionalização normativa de desigualdades entre indivíduos e grupos (Holmes, 2013:120-129). Por outro lado, o direito possibilita à política estruturar seus procedimentos (eleitorais e legislativos), condições para sua diferenciação, tornando possível uma mediação jurídica dos conflitos polí- 
ticos e uma temporalização das suas decisões, que podem ser revistas apenas de acordo com procedimentos definidos juridicamente com base em direitos fundamentais (Luhmann, 1990:180-184; 1993:201-208; Kastner, 2007:75-97). Além disso, a política se aproveita das prestações funcionais do direito positivo como um instrumento para realizar seus possíveis "objetivos", programas teleológicos decididos em instâncias políticas. A constituição político-jurídica pode, assim, ser explicada como uma aquisição evolutiva que oferece "uma solução jurídica para o problema da diferenciação funcional da política e uma solução política para o problema da diferenciação funcional do direito" (Luhmann, 1990:202).

Ainda segundo uma descrição sistêmica, a sociedade mundial moderna é marcada por uma mudança estrutural: uma transição desde uma ordem social ontologicamente hierárquica - na qual há uma prevalência da dimensão social do sentido que atribui status social determinado a cada indivíduo na sociedade de acordo com uma determinada classe ou estrato, por nascimento - para uma ordem social funcionalmente diferenciada, na qual há uma prevalência da dimensão temporal do sentido (Luhmann, 1997b:763, 1005-1015). Dessa forma, na sociedade moderna funcionalmente diferenciada, nenhuma posição social de hierarquia pode se justificar, se não está sujeita a alguma possibilidade de mudança, no tempo, de acordo com a lógica de sistemas funcionais especializados: economia, direito, política, ciência (idem, 2005:244). Toda diferença social deve poder ser temporalizada (Luhmann, 1980:235-299) e cada indivíduo deve ser incluído em sistemas sociais, apenas na medida em que é observada a respectiva lógica de inclusão de determinado sistema funcional. O usufruto de determinado direito não pode resultar dos mecanismos de seleção do sistema político. Assim como a autoridade para exercer o poder não pode derivar diretamente dos mecanismos de seleção do sistema econômico ou do sistema científico. A modernidade funcionalmente diferenciada se constitui, portanto, a partir de mecanismos de quebra da interdependência entre códigos, de modo que aquele que tem dinheiro não poderá dispor, apenas por isso, de poder, de direito ou de saber. Cada esfera funcional reserva para si os critérios de inclusão e exclusão de indivíduos e de reprodução dos seus próprios códigos de comunicação (Luhmann, 1997b:744-750).

Segundo Luhmann, uma sociedade funcionalmente diferenciada "pode tolerar ou produzir desigualdades extremas de distribuição de bens públicos e privados, mas do ponto de vista da sua semântica isso 
só pode acontecer sob duas condições: que essa realidade seja vista como algo apenas temporário e que ela possa mudar de modo extremamente rápido" (2005:249). A sociedade moderna parece então operar com uma necessária suposição semântica da inclusão total de todos os indivíduos em todos os subsistemas (Luhmann, 1997b:627-630). Isso não quer dizer que essa inclusão se realize, mas que ao menos normativamente não se podem mais justificar adscrições atemporalizáveis de status e posições sociais por nascimento. Em última análise, desigualdades devem poder ser atribuídas às dinâmicas contingentes da economia, da política, do direito e das próprias biografias individuais (Stichweh, 2004:71-73). Mas esse fato não pode ser descrito de maneira tão trivial. Ele depende de estruturas sociais bem específicas, que podem ser relacionadas ao processo de constitucionalização política.

O processo de constitucionalização, à medida que estabelece juridicamente direitos fundamentais, funciona como um mecanismo social de imunização contra o risco de desdiferenciação (Luhmann, 1997b:1075-1076). Para Luhmann, os direitos fundamentais consistem em um mecanismo de temporalização que garante "a manutenção da abertura da sociedade ao futuro contra qualquer predefinição, classificação ou divisão dos indivíduos" (ibidem:1075). Por meio do sistema de direitos, o complexo institucional do Estado constitucional exige "não apenas uma inclusão passiva (segurança jurídica), senão também a inclusão ativa (democracia) de interesses no sistema político" e no sistema jurídico (idem, 1981:31). Luhmann identifica, aliás, uma diferença fundamental entre a igualdade jurídica e a igualdade política, que pode nos auxiliar a distinguir os mecanismos de inclusão dos dois sistemas: "A política exige que os indivíduos sejam tratados igualmente; já o direito exige que os casos sejam tratados igualmente" (1993:113). De modo que, ao lado da igualdade de acesso ao sistema jurídico caracterizado pelas garantias de isonomia de tratamento formal e da segurança jurídica, coloca-se igualdade entre todos os indivíduos, no interior do sistema político, caracterizado, por exemplo, pelo sufrágio universal.

Essas são certamente exigências sobretudo normativas, que podem adquirir uma dimensão meramente simbólica, em alguns casos (Neves, 2007:101-104). Ainda assim, instituições constitucionais normativas podem ser capazes de ativar conflitos no interior do sistema político capazes de dar movimento a mecanismos de concretização constituci- 
onal. E em alguma medida eles funcionam como constrangimentos para as estruturas jurídicas.

Mas o que dizer sobre regimes de governança e regimes jurídicos em que não existem os mecanismos de inclusão política? Como se reproduziriam as estruturas jurídicas de ordens transnacionais e supranacionais de regulação social que cada vez mais produzem um "direito sem Estado" e que, portanto, não correspondem à forma política de constitucionalização (Teubner, 2004:7-9; Willke, 2003:80-102)? Como vimos acima, a alternativa mais plausível parece consistir em descrever as novas estruturas regulatórias do direito e do poder levando em conta a emergência, em nível supranacional e transnacional, de um direito que não dispõe de constituição política, embora mantenha seus imperativos internos relativos à igualdade jurídica (Picciotto, 2008:14-22).

Em lugar disso, cada regime regulatório transnacional e/ou supranacional (juridificado ou não) parece dispor de estruturas extremamente especializadas de controle da reflexividade das suas normas. Como aponta Gunther Teubner, a meu ver corretamente - ao menos no que diz respeito a seu diagnóstico sobre o processo de produção regulatória -, sob condições de "constitucionalização espontânea" transnacional, "o direito mundial desenvolve-se a partir da periferia dos sistemas sociais, a partir do contato com outros sistemas sociais, e não apenas do centro representado por instituições políticas nacionais e internacionais" (Teubner, 1997:7). Para ele, um conjunto de "atores civis" privados, organizações e indivíduos emerge como uma periferia de cada setor social regulado capaz de dar movimento a processos de elaboração normativa dotados de um caráter espontâneo. A noção de ordem e normatização social, nesse plano, seria o resultado de acomodações e formações de expectativas sedimentadas, sobretudo, em práticas sociais contratuais, nas quais os atores eles mesmos forjariam e estabilizariam seus mecanismos de interação e as suas respectivas expectativas recíprocas (Teubner, 2004:12-15) ${ }^{9}$.

Contudo, as formas de inclusão de atores sociais em cada um desses regimes globais dependem não de estruturas amplas, flexíveis e temporalizadas de inclusão, como eram aquelas dos direitos fundamentais assentados em uma constituição política. Elas dependem, senão, das contingentes formas de inclusão de cada esfera funcional específica a ser regulada. As condições de inclusão social no regime jurídico da 
OMC, por exemplo, são estabelecidas não de modo positivo e normativo como um direito fundamental que se pode buscar garantir, inclusive, politicamente (ainda quando tenha uma dimensão meramente simbólica), elas dependem das condições econômicas que fazem de um ator social específico (normalmente uma organização) um stakeholder relevante nas estruturas do comércio mundial. Embora sejam os Estados os autorizados a agir contenciosamente na OMC, são normalmente os setores econômicos mais organizados aqueles que têm capacidade de mobilizar recursos para provocar as administrações nacionais no sentido de proteger seus interesses. O mesmo ocorre em outros regimes, como o ICANN, a lex mercatoria ou nos regimes de governança do sistema financeiro global.

Em consequência dessa transformação da forma constitucional, cabe a uma sociologia da constituição refletir sobre possíveis efeitos de longo prazo da ausência daquelas instituições típicas do Estado constitucional democrático, para o conjunto da sociedade. Uma tarefa que outras áreas das Ciências Sociais não se propõem a realizar, seja por não dispor de conceitos, seja por não dispor de interesse. Afinal, se aquilo que a teoria dos sistemas chama uma diferenciação funcional se baseia em alguma medida de temporalização de hierarquias sociais, tornadas criticáveis e politizáveis e, consequentemente, passíveis de serem transformadas mediante mecanismos internos à própria sociedade por meio de mecanismos constitucionais de positivação de direitos, quais seriam os riscos criados pela ausência dos mecanismos de temporalização dessas hierarquias?

Alguns autores, com apoio em uma formulação elaborada de modo apenas parcial por Niklas Luhmann, insistem na possibilidade de que eventos extremos de exclusão ou desrespeito às estruturas normativas da diferenciação funcional, assim como elas se revelam na semântica mundialmente difundida dos direitos humanos, poderiam servir como fonte de irritação no interior dos regimes jurídicos globais, desacoplados politicamente. A escandalização de eventos extremos de exclusão social poderia levar tais sistemas a momentos constitucionais capazes de garantir a emergência dos mecanismos inclusivos de que depende a sociedade mundial moderna para a reprodução de sua forma de diferenciação funcional (Fischer-Lescano, 2005:67-99). A em parte já existente esfera pública mundial, apoiada por processos de escandalização gerados pelas associações entre uma sociedade civil organizada cada vez mais com caráter transnacional e os meios de comu- 
nicação de massa, poderia engendrar uma forma de colère publique mondiale (Fischer-Lescano, 2005:67s), para parafrasear a expressão originalmente utilizada por Émile Durkheim. Esses mecanismos difusos de escandalização funcionariam por sua vez como uma regra de reconhecimento constitucional do direito mundial (no sentido utilizado por Herbert Hart), capazes de cumprir o papel de equivalente funcional daquilo que eram os mecanismos institucionais internos de autoirritação do sistema político no nível dos Estados nacionais.

Do meu ponto de vista, essa assunção se baseia, contudo, em dois pressupostos bastante problemáticos. Primeiramente, ela supõe que a sociedade civil mundial é caracterizada por uma larga simetria e igualdade no acesso aos meios de escandalização. No fundo, ignora-se assim que a sociedade civil organizada já é, muitas vezes, estruturada segundo mecanismos semânticos extremamente seletivos, que fixam alguns problemas específicos como relevantes e deixam uma série de outros temas simplesmente intocados. $\mathrm{O}$ acesso a mecanismos de escandalização para além de fronteiras territoriais exige, já de antemão, um nível de organização que só pode ser atingido com fontes não desprezíveis de financiamento que provêm dos mesmos agentes (corporações, organizações científicas ou mesmo Estados poderosos) que deveriam muitas vezes ser limitados por possíveis processos de constitucionalização globais de direitos humanos e sociais.

Por outro lado, como um pool de valores, tendo à sua disposição apenas uma força simbólica, os direitos humanos parecem ser inábeis para produzir a capacidade interna de irritação ao sistema político que apenas uma esfera pública ativa pode garantir. A força semântica simbólica dos direitos humanos (Neves, 2005) precisa se assentar em estruturas institucionais bem claras para que possam ter alguma função. Como sabemos, um catálogo simbólico de direitos humanos já estava presente na semântica jurídica do constitucionalismo norte-americano, embora a escravidão tenha sido juridicamente aceita até 1863, e uma ampla exclusão - legalmente justificada - de afro-americanos de vários subsistemas ter sido tolerada até os anos 1960 (cf. Neves, 2008a:487). Apenas a política, a democracia e a participação ativa (positiva) de grupos sociais concretos tornaram possíveis novos graus de inclusão social, bem como possibilitam a amplificação do que deveria ser considerado como igual em um sentido jurídico.

As condições estruturais de reprodução do direito e do poder na sociedade mundial atual parecem comprometer exatamente esses pressu- 
postos constitucionais relacionados ao processo de modernização. E as consequências dessa transformação da forma constitucional podem ser dramáticas. Se os sistemas político e jurídico não possuem mais meios para serem irritados (ao menos simbolicamente) por problemas de exclusão social, sendo capazes de dar respostas a esses problemas, é preciso questionar se não é possível que, no longo prazo, a diferença entre inclusão/exclusão possa tornar-se um código com poder de reprogramar os códigos dos diversos sistemas funcionais modernos (Luhmann, 2008:38-46). Essa formulação de Luhmann, que dizia respeito à forma como a exclusão social se prolifera em regiões periféricas da sociedade mundial (cf. Neves, 2008b:236-234), parece ganhar assim um novo significado frente às transformações do direito e da política em nível global. E não parece mero acaso que argumentos que sustentam uma tendência à refeudalização da sociedade mundial parecem ter se tornado, nos últimos anos, mais do que diagnósticos catastróficos e ficcionais (cf. Piketty, 2014:22-28; Neckel, 2010).

Respostas normativas ambiciosas, que apontam para a exigência funcional de uma constitucionalização política mundial como única solução possível para os desafios regulatórios do nosso tempo tampouco parecem ser realistas, ou mesmo desejáveis, se lembrarmos como estruturas políticas supranacionais foram historicamente instrumentalizadas por potências econômicas e militares para produzir relações assimétricas, entre centro e periferias. Se podemos chegar a alguma conclusão, em vista das constatações teóricas acerca das transformações do constitucionalismo, podemos dizer que o grande desafio do nosso tempo, tanto no campo teórico como no campo prático, consiste em imaginar equivalentes funcionais para a política democrática além do Estado nacional.

(Recebido para publicação em maio de 2013)

(Reapresentado em novembro de 2013) (Aprovado para publicação em junho de 2014) 


\section{NOTAS}

1. Distingo, aqui, o nível transnacional como aquele em que processos sociais se reproduzem levando em conta de modo apenas secundário fronteiras fixadas por ordens nacionais, com pretensões de funcionar como ordens soberanas paralelas (heterárquicas) em relação a outras ordens transnacionais ou nacionais. O nível supranacional se referiria a ordens que têm pretensões de se impor de modo hierárquico a ordens nacionais.

2. Essa definição foi dada pelo controverso relatório sobre governança global, chamado Our Global Neighbourhood, produzido por um grupo de experts comissionado pelo primeiro-ministro da Suécia e pelo secretário-geral da Commonwealth em 1995. Ver: Commission on Global Governance, 1995:2-4 (http://www.gdrc.org/u-gov/global-neighbourhood/).

3. Caso notório é o decidido pelo ICSID entre a República do Equador e a Chevron, de acordo com o qual a Chevron negou-se a pagar indenização de 19 bilhões de dólares a que havia sido condenada nacionalmente por danos ambientais. A corte constitucional equatoriana confirmou a validade da condenação, mas a decisão da arbitragem internacional foi favorável à Chevron, que ao final não cumpriu a condenação. Ver: Chevron Corportation and Texaco Petroleum Corporation versus the Republic of Ecuador, UNCITRAL, PCA Case nํㅡ 2009-23.

4. A seguir usarei o conceito genérico de regime de governança (ou simplesmente regime global) para ordens com graus variáveis de formalidade (mais ou menos juridificação) em um sentido mais próximo ao da teoria das relações internacionais, o que englobaria inclusive regimes jurídicos; usarei ainda o conceito, mais específico, de regime jurídico para regimes com maior grau de juridificação, tornando-os equivalentes ao conceito de ordens jurídicas (que exige a pretensão de vinculação social a normas jurídicas). Ainda a título de esclarecimento, o conceito de sistema social é utilizado em termos sociológicos, à luz da teoria dos sistemas. Nesse sentido, falo em sistema político ou jurídico como sistema funcional da sociedade mundial. No contexto teórico da teoria dos sistemas, existem ainda sistemas organizacionais e interacionais (Luhmann, 1997b:812).

5. No caso da União Europeia, embora tentativas de estabelecer um processo constituinte tenham falhado, parece não ser de todo absurdo aceitar a existência de uma constituição política europeia, ainda que esta seja apontada como apenas parcialmente democrática (Brunkhorst, 2012:361-369).

6. Sobre a diversidade de novas formas de colisão que emergem no direito global contemporâneo, ver: Fischer-Lescano e Teubner (2007).

7. Todas as citações de textos publicados em língua estrangeira foram traduzidas livremente pelo autor.

8. Stichweh sugere que o estabelecimento de um possível acoplamento estrutural entre diferentes sistemas sociais também depende de condições semânticas garantidas por suas autodescrições (2000:237-250).

9. Aqui não é difícil notar uma semelhança dessa formulação com a ideia de uma ordem espontânea, formada a partir de atores privados e suas práticas contratuais, assim como proposta por F. Hayek (1945). Klaus Gunther (2003) faz uma referência direta a essa semelhança. 


\section{O Constitucionalismo entre a Fragmentação e a Privatização...}

\section{REFERÊNCIAS BIBLIOGRÁFICAS}

ABBOT, Kenneth W. et al. (2000), “The Concept of Legalization". International Organization, vol. 54, no 3, pp. 401-419.

AMSTUTZ, Marc e KARAVAS, Vaio. (2009), "Weltrecht:Ein Derridarisches Monster", in G.-P. Calliess et al. (orgs.), Soziologische Jurisprudenz, Festschrift für Gunther Teubner zum 65. Geburtstag. Berlin, De Gruyter, pp. 645-672.

BAECKER, Dirk. (2009), "The Power to Rule the World”, in G.-P. Calliess et al. (orgs.), Soziologische Jurisprudenz, Festschrift für Gunther Teubner zum 65. Geburtstag. Berlin, De Gruyter, pp. 673-686.

BECK, Ulrich. (1999), "Weltrisikogesellschaft, Ökologische Krise und Technologiepolitik", in U. Beck et al. (orgs.), Der unscharfe Ort der Politik. Empirische Fallstudien zur Theorie der reflexiven Modernisierung. Frankfurt a/M, Suhrkamp, pp. 307-319

BOHMAN, James. (2004), "Constitution Making and Democratic Innovation: The European Union and Transnational Governance". European Journal of Political Theory, vol. 3, no 3, pp. 315-337.

BRAITHWAITE, John. (2005), “Neoliberalism or Regulatory Capitalism". Regulatory Institutions Network, RegNet Occasional Paper, no 5.

BRUNKHORST, Hauke. (2007), “Die Legitimationskrise der Weltgesellschaft. Global Rule of Law, Global Constitutionalism und Weltstaatlichkeit", in M. Albert e R. Stichweh (orgs.), Weltstaat und Weltstaatlichkeit. Beobachtungen globaler politischer Strukturbildung. Wiesbaden, VS Verlag, pp. 63-109.

. (2009), “Machbarkeitsillusionen, feierliche Erklärungen und Gesänge: Zum Verhältnis von Evolution und Revolution im Recht", in G.-P. Calliess et al. (orgs.), Soziologische Jurisprudenz, Festschrift für Gunther Teubner zum 65. Geburtstag. Berlin, De Gruyter, pp. 447-464.

(2012), Legitimationskrisen. Verfassungsprobleme der Weltgesellschaft. Baden-Baden, Nomos.

(2014), "Decapitação do Legislador: A Crise Europeia: Paradoxos da Constitucionalização do Capitalismo Democrático". Revista Direito. UnB, vol. 1, no 1, pp. 93-118.

CARROLL, William e FENEMA, Meindert. (2002), "Is There a Transnational Business Community?". International Sociology, vol. 17, no 3, pp. 393-419.

CARUSO, Daniela. (2007), "Private Law and State-Making in the Age of Globalization". NYU Journal of International Law and Politics, vol. 12, no 38, pp. 1-74.

CASSESE, Sabino. (2005a), “The Globalization of Law”. NYU Journal of International Law and Politics, vol. 37, no 4, pp. 973-993.

(2005b), “Administrative Law without the State. The Challenge of Global Regulation". NYU Journal of International Law and Politics, vol. 37, no 4, pp. 663-694.

CASTRO, Marcos Faro de. (2014), “Novas Perspectivas Jurídicas sobre a Reforma de Políticas Públicas no Brasil”. Direito.UnB, vol. 1, no 1, pp. 31-61. 


\section{Pablo Holmes}

COMMISSION ON GLOBAL GOVERNANCE. (1995), Our Global Neighborhood. Oxford, Oxford Press. Disponível em http://www.gdrc.org/u-gov/global-neighbourhood/. Acesso em 3/4/2013.

CROUCH, Collin. (2009), "Marketization", in M. Flinders et al. (orgs.), The Oxford Handbook of British Politics. Oxford/New York, Oxford Press, pp. 879-895.

CUTLER, A. Claire. (2004), "Private International Regimes and Interfirm Cooperation", in R. B. Hall e T. J. Biersteker (orgs.), The Emergence of Private Authority in Global Governance. Cambridge, Cambridge University Press, pp. 23-41.

DJELIC, Marie Laure e SAHLIN-ANDERSSON, Kerstin. (2006), “Introduction: A World of Governance: The Rise of Transnational Regulation", in M. Djelic e K. SahlinAndersson (orgs.), Transnational Governance: Institutional Dynamics of Regulation. Cambridge, Cambridge University Press, pp. 1-30.

DRORI, Gili S. e MEYER, John W. (2006), "Scientization: Making a World Safe for Organizing", in M. Djelic e K. Sahlin-Andersson (orgs.),Transnational Governance: Institutional Dynamics of Regulation. Cambridge, Cambridge University Press, pp. 31-52.

FISCHER-LESCANO, Andreas. (2005), Globalverfassung. Die Geltungsbegründung der Menschenrechte. Wiesbaden, Vellbruck.

e TEUBNER, Gunther. (2006), Regime-Kollisionen:zur Fragmentierung des globalen Rechts. Frankfurt, Suhrkamp.

(2007), "Fragmentierung des Weltrechts:Vernetzung globaler Regimes statt etatischer Rechtseinheit", in M. Albert e R. Stichweh (orgs.), Weltstaat und Weltstaatlichkeit. Beobachtungen globaler politischer Strukturbildung. Wiesbaden, VS Verlag, pp. 37-67.

GRIMM, Dieter. (2001), “Die Bedingungen demokratischer Rechtssetzung”, in K. Günther e L. Wingert (orgs.), Die Öffentlichkeit der Vernunft und die Vernunft der Öffentlichkeit. Frankfurt a/M, Suhrkamp, pp. 489-506.

GUNTHER, Klaus. (2003), “(Zivil-)Recht. Kann das Zivilrecht im Zuge der Globalisierung das öffentliche Recht ersetzen?", in C. Joerges e G. Teubner (orgs.), Rechtsverfassungsrecht, Recht-Fertigung zwischen Privatrechtsdogmatik und Gesellschaftstheorie. Baden-Baden, Nomos, pp. 295-309.

HAAS, Peter. (1992), "Introduction. Epistemic Communities and International Policy Coordination". International Organization, vol. 46, no 1, pp. 1-35.

HALL, Rodney Bruce e BIERSTEKER, Thomas J. (2006), "The Emergence of Private Authority in the International System", in R. B. Hall e T. J. Biersteker (orgs.), The Emergence of Private Authority in Global Governance. Cambridge, Cambridge University Press, pp. 3-22.

HATZIMIHAIL, Nikitas. (2008), "The Many Lives - and Faces - of Lex Mercatoria: History as Genealogy in International Law Business". Law and Comtemporary Problems, vol. 71, pp. 168-190.

HAYEK, Friedrich. (1945), "The Use of Knowledge in Society". American Economic Review, vol. 35 , no 4 , pp. 519-530.

HEYVAERT, Veerle. (2009), "Hybrid Norms in International Law". London School for Economics: Law, Society and Economy Working Papers 6. Disponível em 


\section{O Constitucionalismo entre a Fragmentação e a Privatização...}

http:/ / ww.lse.ac.uk/collections/law/wps/wps.htm. Acesso em 10 de setembro de 2011.

HIGGINS, Winton e HALLSTRÖM, Kristina T. (2007), “Standardization, Globalization and Rationalities of Government". Organization, vol. 14, no 5, pp. 685-704.

HOLMES, Pablo. (2013), Verfassungsevolution in der Weltgesellschaft. Differezierungsprobleme des Rechts und der Politik im Zeitalter der Global Governance. Baden-Baden, Nomos.

HOWSE, Robert. (2002), "From Politics to Technocracy and Back Again - The Fate of the Multinational Trade Regime". The American Journal of International Law (Symposium: Boundaries of the WTO) no 6, pp. 94-117.

KASTNER, Fatima. (2007), "Luhmanns Souveränitätsparadox: Zum generativen Mechanismus des politischen Systems der Weltgesellschaft", in M. Neves e M. Voigt (orgs.), Die Staaten der Weltgesellschaft: Niklas Luhmanns Staatsverständnis, Baden-Baden, Nomos, pp. 75-97.

KENNEDY, David. (2005), “Challenging Expert Rule: The Politics of Global Governance". Sydney Law Review, vol. 27, no 1, pp. 5-28.

. (2009), "The Mystery of Global Governance", in J. Dunoff e J. Trachtman (orgs.), Ruling the World: Constitutionalism, International Law and Global Governance. Cambridge, Cambridge University Press, pp. 37-67.

KEOHANE, Robert. (1984), After Hegemony: Cooperation and discord in the World Political Economy. Princeton, Princeton University Press.

. (2002), "Governance in a Partially Globalized World", in Power and Governance in a Partially Globalized World. New York, Routledge, pp. 245-271.

KOSKENNIEMI, Martti. (1990), “The Politics of International Law”. European Journal of International Law, vol. 1, no 1, pp. 7-19.

. (2007), "The Fate of International Public Law: Between Technique and Politics". The Modern Law Review, vol. 70, no 1, pp. 1-30.

. (2008), “Formalismus, Fragmentierung, Freiheit: Kantische Themen im heutigen Völkerrecht", in R. Kreide e A. Niederberger (orgs.), Transnationale Verrechtlichung: Nationale Demokratien im Kontext globaler Politik. Frankfurt a/M, Campus, pp. 65-89.

. (2009), "Legal Fragmentation: An Essay on Fluidity and Form", in G.-Peter Calliess et al. (orgs.), Soziologische Jurisprudenz, Festschrift für Gunther Teubner zum 65. Geburtstag. Berlin, De Gruyter, pp. 95-97.

KRASNER, Stephen. (1982), "Structural Causes and Regime Consequences". International Organization, vol. 36, no 2, pp. 185-205.

KRISCH, Niko. (2006), "The Pluralism of Global Administrative Law”. European Journal of International Law, vol. 17, n으, pp. 247-278.

LANG, Andrew e SCOTT, John. (2009), “The Hidden World of WTO Governance”. European Journal of International Law, vol. 20, no 3, pp. 601-614.

LUHMANN, Niklas. (1980), “Temporalisierung von Komplexität: Zur Semantik neuzeitlicher Zeitbegriff", in N. Luhmann, Gesellschaftsstruktur und Semantik. Studien zur Wissenssoziologie der modernen Gesellschaft, Band 1. Frankfurt a/M, Suhrkmap, pp. 235-299. 


\section{Pablo Holmes}

. (1981), Politische Theorie im Wohlfahrtsstaat, München-Wien, Günter Olzog Verlag.

. (1990), "Verfassung als evolutionäre Errungenschaft". Rechtshistorisches Journal, vol. 9, pp. 176-220.

(1993), Das Recht der Gesellschaft. Frankfurt a/M, Suhrkamp.

. (1997a), "Globalization or World Society? How to Conceive of Modern Society?". International Review of Sociology, vol. 7, no 1, pp. 67-80.

(1997b), Die Gesellschaft der Gesellschaft. Frankfurt a/M, Suhrkamp.

(2000), Die Politik der Gesellschaft. Frankfurt a/M, Suhrkamp.

(2005), "Inklusion und Exklusion", in N. Luhmann, Soziologische Aufklärung 6. Die Soziologie und der Mensch. Wiesbaden, VS Verlag, pp. 237-264.

(2008), "Beyond Barbarism". Soziale Systeme, vol. 14, pp. 38-46.

MANN, Michael. (2010), "Globalization, Macro-regions and Nation-States", in G. Budde e S. Conrad (orgs.), Transnationale Geschichte: Themen, Tendenzen und Theorien. Bonn, Vanderhöck e Ruprecht, pp. 21-32.

NECKEL, Sighard. (2010), Refeudalisierung der Oekonomie. Zum Strukturwandel kapitalistischer Wirtschaft. MPIfG Working Paper 10/6 [online], Max-Planck Institute for the Study of Societies, Cologne, [09-03-2012]. Disponível em http:/ / www.mpifg. de. Acesso em 23/10/2011.

NEVES, Marcelo. (2005), "Die symbolische Kraft der Menschenrechte". Archiv für Rechts- und Sozialphilosophie (ARSP), vol. 90, no 2, pp. 159-187.

. (2007), Constitucionalização Simbólica. São Paulo, Martins Fontes.

. (2008a), "Verfassung und Öffentlichkeit, Zwischen Systemdifferenzierung, Inklusion und Anerkennung". Der Staat. Zeitschrift für Staatslehre und Verfassungsgeschichte deutsches und europäisches öffentliches Recht, vol. 47, no 4, pp. 477-509.

. (2008b), Entre Têmis e Leviatã: Uma Relação Difícil. São Paulo, Martins Fontes.

(2009), Transconstitucionalismo. São Paulo, Martins Fontes.

PICCIOTTO, Sol. (1997). “Networks in International Economic Integration: Fragmented States and the Dilemmas of Neo-Liberalism". Northwestern Journal of International Law \& Business, vol. 17, № 2-3, pp. 1014-1056.

. (2008), "Constitutionalizing Multilevel Governance?". International Journal of Constitutional Law, vol. 6, no 3-4, pp. 1-22.

. (2011), Regulating Global Corporate Capitalism. Cambridge, Cambridge University Press.

PIKETTY, Thomas. (2014), Capital in the Twenty-First Century. Cambridge, Harvard University Press (Kindle edition).

RENNER, Moritz. (2011), Zwingendes transnationales Recht. Zur Strktur der Wirtschaftsverfassung jenseits des Staates. Baden-Baden, Nomos.

ROSGA, AnnJanette e SATTERTHWAITE, Margaret L. (2009), "The Trust in Indicators: Measuring Human Rights". Berkeley Journal of International Law, vol. 27, no 2, pp. 253-315. 
SANTOS, Álvaro. (2006), “The World Bank's Uses of the 'Rule of Law' Promise in Economic Development", in A. Santos e D. Trubek (orgs.), The New Law and Economic Development: A Critical Appraisal. Cambridge, Cambridge University Press, pp. 253-300.

SLAUGHTER, Anne-Marie. (1997), The New World Order. Princeton, Princeton University Press.

(2010), “Global Government Networks, global Information Agencies, and Disaggregated Democracy". Harvard Law School Public Law, Working Paper 018. Disponível em http:/ / papers.ssrn.com/abstract=283976. Acesso em 12/9/2010.

STICHWEH, Rudolf. (2000), "Semantik und Sozialstruktur. Zur Logik einer systemtheoretischen Unterscheidung". Soziale Systeme, no 6, pp. 237-250.

. (2004), Inklusion und Exklusion. Studien zur Gesellschaftstheorie. Frankfurt a/M, Transkript.

STOLLEIS, Michael. (2004), “Was kommt nach dem souveränen Nationalstaat? Und was kann die Rechtsgeschicte dazu sagen?", in A. Héritier; M. Stolleis e F. W. Scharpf (orgs.), European and International Regulation after the Nation State: Different Scopes and Multiple Levers. Baden-Baden, Nomos, pp. 17-30.

TEUBNER, Gunther. (1996), "Altera Pars Audiatur: Das Recht in der Kollision anderer Universalitätsansprüche”. Archiv für Rechts- und Sozialphilosophie (ARSP), vol. 65, pp. 199-220.

. (1997), "Global Bukowina. Legal Pluralism in the World Society", in G. Teubner (org.), Global Law Without a State. Brookfield, Dartmouth, pp. 3-28.

. (2004), "Societal Constitutionalism: Alternatives to State-Centred Constitutional Theory?", in C. Joerges et al. (orgs.), Transnational Governance and Constitutionalism. Oxford, Hart Press, pp. 3-29.

. (2012), Verfassungsfragemente. Gesellchaftlicher Konstitutionalismus in der Globalisierung. Frankfurt a/M, Suhrkamp.

TOMUSCHAT, Christian. (1993), “Obligations Arising for States without or against Their Will". Recueil des Cours, vol. 241, The Hague.

VASILACHE, Andreas. (2009), "The Rise of Executive Sovereignty in the Era of Globalization". Institut für Weltgesellschaft an der Universität Bielefed, Working Paper 03/2009. Disponível em http://www.edit.unibielfeld.de/soz/iw/publikationen/ workingpaper_gk/WP_2009_03_Vasilache_executive_sovereignty.pdf. Acesso em $30 / 6 / 2011$.

VESTING, Thomas. (2009), "Politische Verfassung? Der moderne (liberale) Verfassungsbrgriff und seine systemtheoretische Rekonstruktion", in G.-P. Calliess et al. (orgs.), Soziologische Jurisprudenz, Festschrift für Gunther Teubner zum 65. Geburtstag. Berlin, De Gruyter, pp. 609-626.

VON BERNSTORFF, Jochen. (2004), "The Structural Limitations of Network Governance: ICANN as a Case in Point", in C. Joerges et al. (orgs.), Transnational Governance and Constitutionalism. Oxford, Hart Press, pp. 257-281.

WALKER, Neil. (2002), "The Idea of Constitutional Pluralism". The Modern Law Review, vol. 65 , no 3, pp. 317-583. 


\section{Pablo Holmes}

WEILER, John. (2001), "The Rule of Lawyers and the Ethos of Diplomats, Reflections on the Internal and External Legimitimacy of WTO Dispute Settlement". Journal of World Trade, vol. 35, no 2, pp. 191-207.

WILLKE, Helmut. (2003), Heterotopia:Studien zur Krisis der Odnung moderner Gesellschaften. Frankfurt a/M, Suhrkamp.

ZARING, David. (2004), "Informal Procedure, Hard and Soft, in International Administration". Chicago Journal of International Law, vol. 5, no 2, pp. 547-604. 
O Constitucionalismo entre a Fragmentação e a Privatização...

\title{
RESUMO
}

O Constitucionalismo entre a Fragmentação e a Privatização: Problemas Evolutivos do Direito e da Política na Era da Governança Global

O presente artigo trata do debate em curso na teoria política e teoria constitucional, acerca de problemas de constitucionalização de regimes regulatórios transnacionais e supranacionais desde a perspectiva de uma teoria dos sistemas. Ele se volta aos conhecidos problemas de fragmentação do direito e emergência de novas formas de colisão entre regimes, que alteram os mecanismos de funcionamento e exercício do poder. Nas formas emergentes de administração do direito e do poder regulatório em nível transnacional e supranacional, os mecanismos modernos de democracia política parecem perder seu poder de vinculação. Isso parece ter consequências drásticas para os imperativos modernos de inclusão social.

Palavras-chave: transnacionalização; fragmentação do direito; constitucionalismo global; inclusão social

\begin{abstract}
Constitutionalism between Fragmentation and Privatization: Arising Issues in Law and Politics in the Era of Global Governance

This article engages with the ongoing debate in political theory and constitutional theory regarding the issues that arise from the constitutionalization of regulatory transnational and supranational regimes from the perspective of a social systems theory. Particularly, it focuses on the fragmentation of law and its effect on the exercise of power which in turn leads to new forms of private authority and political clashes which cannot be solved through traditional mechanisms of national constitutionalism. The article concludes claiming that fragmented law is at odds with the modern imperatives of social inclusion.
\end{abstract}

Keywords: trans-nationalization; fragmentation of law; global constitutionalism; social inclusion 


\section{RÉSUMÉ}

Le Constitutionnalisme entre la Fragmentation et la Privatisation: Problèmes Évolutifs du Droit et de la Politique à l'Ère de la Gouvernance Mondiale

Cet article porte sur le débat en cours dans la théorie politique et la théorie constitutionnelle, sur les problèmes de constitutionnalisation des régimes réglementaires transnationaux et supranationaux du point de vue de la théorie des systèmes. Il se tourne vers les problèmes connus de la fragmentation du droit et de l'émergence de nouvelles formes de collision entre des régimes qui modifient les mécanismes de fonctionnement et exercice du pouvoir. Dans les formes émergentes d'administration de la loi et du pouvoir réglementaire au niveau transnational et supranational, les mécanismes modernes de la démocratie politique semblent perdre leur pouvoir de contrainte. Cela semble avoir des conséquences dramatiques pour les impératifs modernes de l'inclusion sociale.

Mots-clés: transnationalisation; fragmentation de la loi; constitutionnalisme mondial; inclusion sociale

\section{RESUMEN}

El Constitucionalismo entre la Fragmentación y la Privatización: Problemas Evolutivos del Derecho y de la Política en la Era de la Gobernanza Global

Este artículo discute el debate en curso en la teoría política y en la teoría constitucional sobre los problemas de constitucionalización de regímenes regulatorios transnacionales y supranacionales a partir de la perspectiva de una teoría de los sistemas. Se discuten los conocidos problemas de fragmentación del derecho y la emergencia de nuevas formas de colisión entre regímenes, que modifican los mecanismos de funcionamiento y ejercicio del poder. En las formas emergentes de administración del derecho y del poder regulatorio a nivel transnacional y supranacional, los mecanismos modernos de democracia política parecen perder su poder de vinculación. Esto parece tener consecuencias drásticas para los imperativos modernos de inclusión social.

Palabras clave: transnacionalización; fragmentación del derecho; constitucionalismo global; inclusión social 